\title{
Politique
}

Politique

\section{Beaulieu, H. Galarneau, S. Girard, G. Hervouet, J.-Cl. Labelle et I. Louthood, Présence internationale du Québec : Chronique des années 1978-1983, sous la direction de G. Hervouet et $\mathrm{H}$. Galarneau, Québec, CQRI, 1984, 368 p.}

\section{P. Soldatos}

Numéro 7, hiver 1985

Projection internationale du Québec

URI : https://id.erudit.org/iderudit/040483ar

DOI : https://doi.org/10.7202/040483ar

Aller au sommaire du numéro

Éditeur(s)

Société québécoise de science politique

ISSN

0711-608X (imprimé)

1918-6584 (numérique)

Découvrir la revue

Citer ce compte rendu

Soldatos, P. (1985). Compte rendu de [C. Beaulieu, H. Galarneau, S. Girard, G.

Hervouet, J.-Cl. Labelle et I. Louthood, Présence internationale du Québec :

Chronique des années 1978-1983, sous la direction de G. Hervouet et H.

Galarneau, Québec, CQRI, 1984, 368 p.] Politique, (7), 119-120.

https://doi.org/10.7202/040483ar 
C. Beaulieu, H. Galarneau, S. Girard, G. Hervouet, J.-Cl. Labelle et I. Louthood, Présence internationale du Québec: Cbronique des années 1978-1983, (sous la direction de G. Hervouet et $\mathrm{H}$. Galarneau), Québec, CQRI, 1984, 368 p.

Cette chronique sur la présence internationale du Québec durant la période 1978-1983 est d'une utilité multidimensionnelle.

- Elle nous informe de façon fort circonstanciée sur l'activité internationale d'une Province qui a été, depuis les années soixante, à l'origine d'un processus soutenu et diversifié de promotion du rôle des unités fédérées en politique extérieure.

- Elle fournit de fort utiles données statistiques, événementielles et bibliographiques sur cette débordante activité internationale.

- Elle propose un cadre rigoureux de classification géographique et fonctionnelle qui révèle une vaste connaissance des dossiers rassemblés.

- On y trouve, également une solide base empirique pouvant alimenter et sous-tendre les essais de théorisation qui se développent depuis plusieurs années sur le rôle de politique extérieure des unités fédérées.

- D'un point de vue comparatif, cette réalité événementielle intéressera tous ceux qui cherchent à identifier un cadre de comparaison quantitative et qualitative du rôle international des Provinces canadiennes et, de façon plus générale, des diverses unités fédérées.

- Bien introduit, enfin, du point de vue de l'encadrement de classification systématique et des objectifs et paramètres de la démarche, l'ouvrage propose une lecture bien guidée de cette matière.

Aussi, cet effort collectif constitue-t-il à la fois un outil d'information, un banc d'observation et une base empirique de recherche et de théorisation. Adressé à l'étudiant et au chercheur 
en quête d'information et de thèmes de réflexion et d'analyse ainsi qu'aux décideurs désireux d'information synthétisée et d'une classification systématique, cet ouvrage collectif représente une heureuse initiative du CQRI et de ses collaborateurs s'ajoutant à la mine de données et informations de la «Chronique des relations extérieures du Québec», paraissant dans la revue «Études internationales».

P. Soldatos,

Université de Montréal. 